\title{
Correction to: Differential expression of major genes involved in the biosynthesis of aliphatic glucosinolates in intergeneric Baemoochae (Brassicaceae) and its parents during development
}

\author{
Adji Baskoro Dwi Nugroho ${ }^{1}$. Narae Han ${ }^{1}$. Aditya Nurmalita Pervitasari ${ }^{1}$. Dong-Hwan Kim ${ }^{1}$ • Jongkee Kim ${ }^{1}$
}

Published online: 29 January 2020

(c) Springer Nature B.V. 2020

Correction to: Plant Molecular Biology (2020) 102:171-184 https://doi.org/10.1007/s11103-019-00939-2

Due to an unfortunate turn of events, an incorrect note was provided in the original publication as it should have read:

Acknowledgements This research was supported by the CAYSS Program of Chung-Ang University to A.B.D.N. and A.N.P., and the startup funds (201801238-001-00) from Chung-Ang University to D.-H. K.
Publisher's Note Springer Nature remains neutral with regard to jurisdictional claims in published maps and institutional affiliations.

The original article can be found online at https://doi.org/10.1007/ s11103-019-00939-2.

Dong-Hwan Kim

dhkim92@cau.ac.kr

$\triangle$ Jongkee Kim

jkkim@cau.ac.kr

1 Department of Plant Science and Technology, Chung-Ang

University, Anseong 17546, Republic of Korea 